\title{
Estimation of Maximum Solid Solubility in Mg-Hg Alloys by the Lever Rule
}

\author{
Libo Wang ${ }^{1, *}$, Peijie $\mathrm{Li}^{1}$ and Liangju $\mathrm{He}^{2}$ \\ ${ }^{1}$ National Center of Novel Materials for International Research, Tsinghua University, Beijing 100084, P. R. China \\ ${ }^{2}$ School of Aerospace, Tsinghua University, Beijing 100084, P. R. China
}

\begin{abstract}
The microstructures of $\mathrm{Mg}-\mathrm{Hg}$ alloys with 1.1-2.9 mass\% $\mathrm{Hg}$ were investigated in this paper. Under the non-equilibrium solidification condition, the examined $\mathrm{Mg}-\mathrm{Hg}$ alloys had a two-phase structure consisting of a solid solution phase and a spheroidal-graphite iron-like divorced eutectic. Eutectic $\alpha-\mathrm{Mg}$ and eutectic $\mathrm{Mg}_{3} \mathrm{Hg}$ formed separately, so the proportion of eutectic $\mathrm{Mg}_{3} \mathrm{Hg}$ could be accurately measured. A method was proposed to estimate the maximum solid solubility of $\mathrm{Hg}$ in $\mathrm{Mg}$ under the non-equilibrium solidification condition by measuring the area fraction of $\mathrm{Mg}_{3} \mathrm{Hg}$ in metallographes. The maximum solid solubility of $\mathrm{Mg}-2.4$ mass $\% \mathrm{Hg}$ was 0.81 and 0.69 mass\%, with cooling rates of 0.67 and $2.0 \mathrm{~K} / \mathrm{s}$, respectively. The maximum solid solubility decreased as the cooling rate increased and increased as the Hg content increased. [doi:10.2320/matertrans.M2012272]
\end{abstract}

(Received August 10, 2012; Accepted November 21, 2012; Published December 28, 2012)

Keywords: magnesium-mercury alloy, divorced eutectic, phase diagrams, maximum solid solubility, metals and alloys

\section{Introduction}

Magnesium alloys as anodes of seawater batteries are widely used in torpedos, pharos and life jackets due to their high specific energy, long storage life, stable discharge ability and rapid activation. ${ }^{1)}$ The currently used magnesium alloy anode materials include mainly $\mathrm{Mg}-\mathrm{Al}$ alloys, such as AZ31, AZ61 and AP65. ${ }^{2)}$ AZ31 and AZ61 are not suitable as battery anodes in some systems. The specific energy of a battery with AP65 is less than $100 \mathrm{Wh} / \mathrm{kg}^{3)} \mathrm{Mg}-\mathrm{Hg}$ alloys with $1-$ 3 mass $\% \mathrm{Hg}$ are among the best anode materials for seawater batteries. ${ }^{4)}$ Intermetallic compound $\mathrm{Mg}_{3} \mathrm{Hg}$, which formed by adding an appropriate amount of $\mathrm{Hg}$, could inhibit microgalvanic corrosion and prevent the formation of thick corrosion product films on the matrix surfaces; the second phase of $\mathrm{Mg}_{3} \mathrm{Hg}$ can also activate the magnesium matrix, improve peak voltage and effective discharge time. For magnesium alloy anode materials, the content of alloying elements is an important factor in determining performance. Magnesium alloys with the alloying element's content near its maximum solubility have better electrochemical performance. ${ }^{5)}$ When the content of $\mathrm{Hg}$ exceeds the maximum solid solubility, $\mathrm{Hg}$ is detrimental to corrosion performance and accelerates microgalvanic corrosion. ${ }^{6}$ )

Under the equilibrium solidification condition, the solid solution of $\mathrm{Hg}$ in $\mathrm{Mg}$ is 3.6 mass\% at $721 \mathrm{~K}$ and 0.9 mass\% at $673 \mathrm{~K}^{7}{ }^{7}$ The actual solidification conditions for preparing $\mathrm{Mg}-\mathrm{Hg}$ alloys are mostly non-equilibrium. Understanding the change in maximum solid solubility under non-equilibrium is important in improving the electrochemical properties of $\mathrm{Mg}-\mathrm{Hg}$ alloys. Vyazer measured the partial vapor pressure of $\mathrm{Hg}$ and determined that the solid solution of $\mathrm{Hg}$ in $\mathrm{Mg}$ is 0.93 mass $\%$ at $721 \mathrm{~K}$ with a $0.24 \mathrm{~K} /$ s cooling rate. $^{8)}$

Mercury poisoning is a disease caused by prolonged contacting simple substance $\mathrm{Hg}$ or inhaling of $\mathrm{Hg}$ vapor. Because toxic element of $\mathrm{Hg}$ is used in this product, the safety of using and producing these alloys must be considered. Alloys used in these products only have little content of $\mathrm{Hg}$. $\mathrm{Hg}$ element exists in the form of solid solution

*Corresponding author, E-mail: wlb@mails.tsinghua.edu.cn and intermetallic compound, no simple substance exists in alloys. Users can't direct contact with these products, which only used as battery anode plates. In order to reduce the generation of $\mathrm{Hg}$ vapor in production process, the intermediate alloys were prepared using the following method. A hole was drilled in the surface of a magnesium block, in which a certain weight of $\mathrm{Hg}$ was placed. Then the hole was plugged with a magnesium stopper. The block was placed in resistance furnace filled with Ar atmosphere and was heated at $600 \mathrm{~K}$ for $30 \mathrm{~min}$ to form the $\mathrm{Mg}-\mathrm{Hg}$ master alloy.

\section{Experimental}

Because $\mathrm{Hg}$ is volatile at high temperatures, $\mathrm{Mg}-\mathrm{Hg}$ master alloys with 10 mass $\% \mathrm{Hg}$ were pre-prepared. The method of master alloy preparation was described earlier. $\left.{ }^{6}\right)$ The other alloys were obtained by diluting this master alloy. This method not only ensures accurate compositions but also guarantees identical nucleation conditions. The steel mold was in the shape of diameter cylinder as shown in Fig. 1. The cooling rates of the alloys were determined by measuring the secondary dendrite arm spacing and using the eq. (1), where $D$ is the secondary dendrite arm spacing, $V$ is the cooling rate, $\beta$ is a constant which is equal to 100 in this casting system. ${ }^{9)}$

$$
D=\beta V^{-1 / 3}
$$

The results were $0.67 \mathrm{~K} / \mathrm{s}$ near the center (sample $\mathrm{A}$ in Fig. 1) and $2.0 \mathrm{~K} / \mathrm{s}$ near the edge (sample B in Fig. 1). For non-equilibrium solidification, cooling rate is an important parameter. The larger the cooling rate, the greater the compositions of primary $\alpha-\mathrm{Mg}$ deviation from the equilibrium phase diagram. $\mathrm{Mg}-\mathrm{Hg}$ alloys are susceptible to corrosion, so polishing requires the use of alcohol.

\section{Results and Discussion}

Figure 2 shows the as-cast microstructures of the $\mathrm{Mg}-\mathrm{Hg}$ alloys with different $\mathrm{Hg}$ contents. Metallographic analysis shows that the microstructures of the $\mathrm{Mg}-\mathrm{Hg}$ alloys with $\mathrm{Hg}$ contents ranging from 1.1 to 2.9 mass $\%$ are similar. The main area is primary $\alpha-\mathrm{Mg}$ (panel A). Eutectic phases distribute 


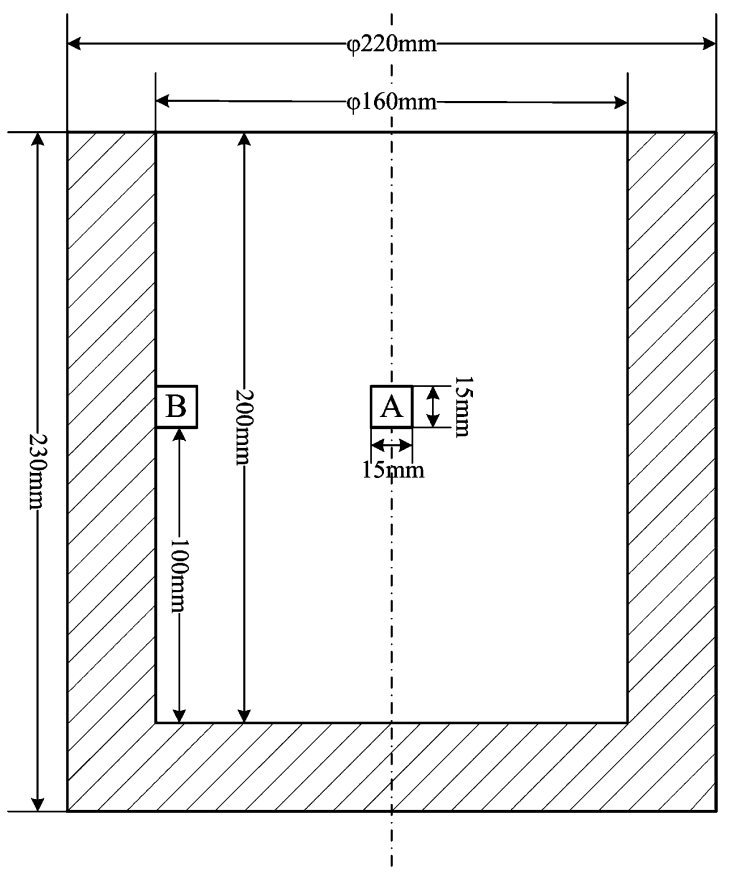

Fig. 1 Schematic drawing of the permanent mould.
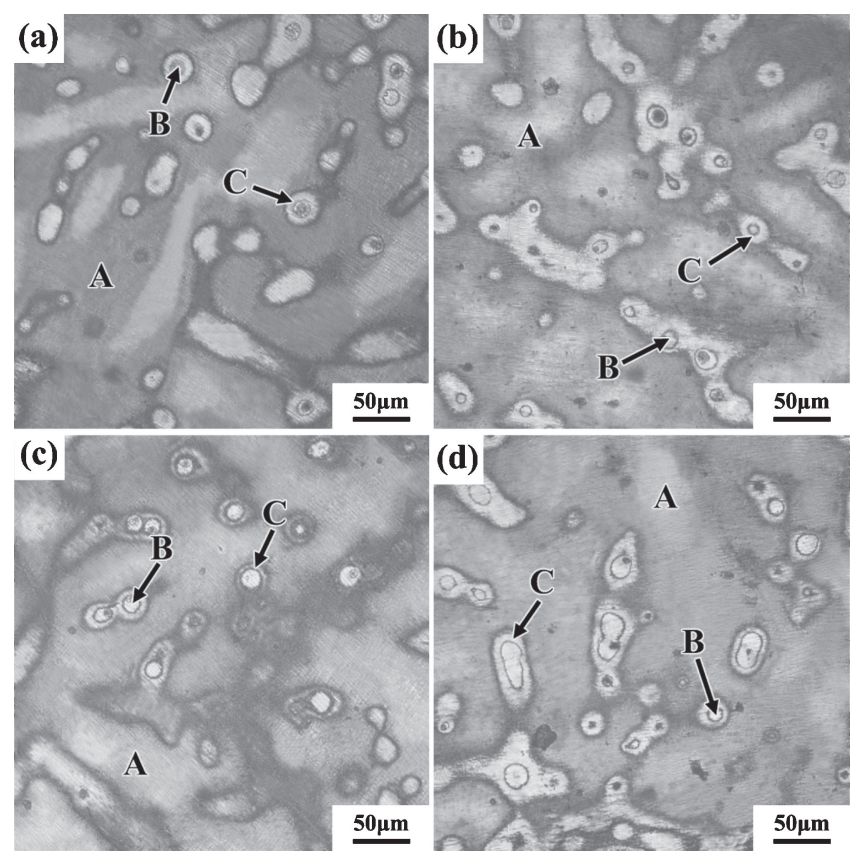

Fig. 2 Microstructures of $\mathrm{Mg}-\mathrm{Hg}$ alloys under a $0.67 \mathrm{~K} / \mathrm{s}$ cooling rate.

(a) $\mathrm{Mg}-1.1$ mass $\% \mathrm{Hg}$, (b) $\mathrm{Mg}-1.8$ mass $\% \mathrm{Hg}$, (c) $\mathrm{Mg}-2.4$ mass $\% \mathrm{Hg}$ and (d) $\mathrm{Mg}-2.9$ mass $\% \mathrm{Hg}$.

not only at the grain boundaries but also inside the grains. The eutectic morphology of $\mathrm{Mg}-\mathrm{Hg}$ alloys is divorced eutectic, similar to spheroidal-graphite iron. ${ }^{10)}$ The spherical particles were eutectic $\mathrm{Mg}_{3} \mathrm{Hg}$ (panel B), which were completely surrounded by the eutectic $\alpha-\mathrm{Mg}$ (panel C). As shown in Fig. 2, the amount of eutectic $\mathrm{Mg}_{3} \mathrm{Hg}$ increased with as the $\mathrm{Hg}$ content increased. Increasing the $\mathrm{Hg}$ content to 2.4 mass $\%$ changes the eutectic at the grain boundary from a discontinuous to a continuous network.

The complete $\mathrm{Mg}-\mathrm{Hg}$ phase diagram is very complex. ${ }^{11)}$ The alloys studied in this paper only appear within the

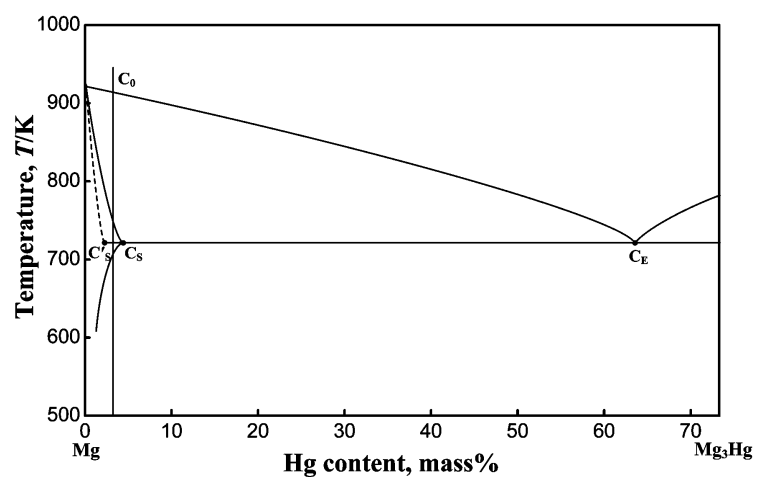

Fig. 3 Schematic of the equilibrium and non-equilibrium (dashed line) phase diagram for the $\mathrm{Mg}-\mathrm{Hg}$ system at $\mathrm{Mg}$ end.

hypoeutectic region shown in Fig. 3. According to the $\mathrm{Mg}-$ $\mathrm{Hg}$ equilibrium phase diagram, the eutectic at the $\mathrm{Mg}$ end consisted of $\alpha-\mathrm{Mg}$ and $\mathrm{Mg}_{3} \mathrm{Hg}$. The maximum solid solubility at the eutectic temperature is approximately 3.6 mass $\% \mathrm{Hg}$. All of the alloys used in this experiment were below the maximum solid solubility; therefore, the microstructure should be only $\alpha-\mathrm{Mg}$. The presence of eutectic phases in these alloys suggests irregular solidification. Lipchin showed that even with an extremely slow cooling rate $(0.0083 \mathrm{~K} / \mathrm{s})$, the eutectic of the $\mathrm{Mg}-\mathrm{Hg}$ alloy with 3 mass $\% \mathrm{Hg}$ precipitates in the grain boundaries. ${ }^{12)}$ A similar phenomenon was observed in a $\mathrm{Mg}-\mathrm{Al}$ system, in which the maximum solid solubility of $\mathrm{Al}$ decreased from 12.6 to 2 mass $\%$ with cooling rate of $0.017 \mathrm{~K} / \mathrm{s}{ }^{13}$ )

From the non-equilibrium phase diagram shown in Fig. 3, eq. (2) can be obtained through the lever rule. $\left.{ }^{14}\right)$

$$
\frac{M_{\mathrm{Mg}}}{M_{\mathrm{E}}}=\frac{C_{\mathrm{E}}-C_{0}}{C_{0}-C_{\mathrm{S}}^{\prime}}
$$

$M_{\mathrm{Mg}}$ is the mass fraction of primary $\alpha-\mathrm{Mg}$ at the eutectic temperature, $M_{\mathrm{E}}$ is the mass fraction of the eutectic at the eutectic temperature, $C_{\mathrm{E}}$ is the $\mathrm{Hg}$ content at the eutectic point, $C_{0}$ is the $\mathrm{Hg}$ content of the $\mathrm{Mg}-\mathrm{Hg}$ alloy, and $C_{\mathrm{S}}^{\prime}$ is the maximum solid solution of $\mathrm{Hg}$ in $\mathrm{Mg}$ under the nonequilibrium solidification condition.

When the eutectic transformation of $\mathrm{Mg}-\mathrm{Hg}$ alloy occurs, eutectic $\alpha$ - $\mathrm{Mg}$ and eutectic $\mathrm{Mg}_{3} \mathrm{Hg}$ form separately. $M_{\mathrm{E}}$ could be divided into $M_{\mathrm{MH}}$ and $M_{\mathrm{E}-\mathrm{Mg}}$, where $M_{\mathrm{MH}}$ is the mass fraction of eutectic $\mathrm{Mg}_{3} \mathrm{Hg}$ and $M_{\mathrm{E}-\mathrm{Mg}}$ is the mass fraction of eutectic $\alpha$-Mg.

The mass fraction of eutectic $\mathrm{Mg}_{3} \mathrm{Hg}$ can be calculated with the lever rule.

$$
\frac{M_{\mathrm{MH}}}{M_{\mathrm{E}}}=\frac{C_{\mathrm{o}}-C_{\mathrm{S}}^{\prime}}{C_{\mathrm{MH}}-C_{\mathrm{S}}^{\prime}}
$$

The mass of the unit can be assumed to be 1 .

$$
M_{\mathrm{Mg}}=1-M_{\mathrm{E}}
$$

Substituting eqs. (3) and (4) into eq. (2).

$$
M_{\mathrm{MH}}=\frac{C_{\mathrm{o}}-C_{\mathrm{S}}^{\prime}}{C_{\mathrm{MH}}-C_{\mathrm{S}}^{\prime}}
$$

If the distribution of $\mathrm{Mg}_{3} \mathrm{Hg}$ in the alloy is uniform, then the volume ratio of $\mathrm{Mg}_{3} \mathrm{Hg}$ is equal to the area ratio. The volume ratio of $V_{\mathrm{MH}}$ to $V$ can be written as eq. (6). 


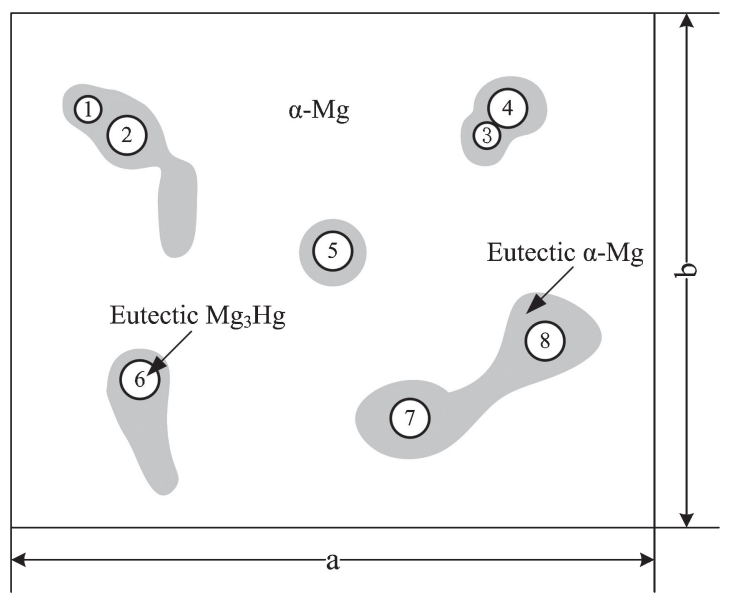

Fig. 4 Schematic of quantitative metallography method.

$$
\frac{V_{\mathrm{MH}}}{V}=\frac{M_{\mathrm{MH}} \cdot \rho}{\rho_{\mathrm{MH}}}=\frac{\left(C_{\mathrm{o}}-C_{\mathrm{S}}^{\prime}\right) \cdot \rho}{\left(C_{\mathrm{MH}}-C_{\mathrm{S}}^{\prime}\right) \cdot \rho_{\mathrm{MH}}}=\frac{S_{\mathrm{MH}}}{S}
$$

$\rho_{\mathrm{MH}}$ is the density of $\mathrm{Mg}_{3} \mathrm{Hg}$, and $\rho$ is the density of $\mathrm{Mg}-\mathrm{Hg}$ alloys.

The maximum solid solution of $\mathrm{Hg}$ in $\mathrm{Mg}$ under the nonequilibrium solidification condition can be expressed as eq. (7).

$$
C_{\mathrm{S}}^{\prime}=\frac{\frac{S_{\mathrm{MH}}}{S} \cdot \rho_{\mathrm{MH}} \cdot C_{\mathrm{MH}}-C_{0} \cdot \rho}{\frac{S_{\mathrm{MH}}}{S} \cdot \rho_{\mathrm{MH}}-\rho}
$$

According to the known parameters, $\rho_{\mathrm{MH}}=5110 \mathrm{~kg} / \mathrm{m}^{3}$ and $C_{\mathrm{MH}}=73.3$.

The density of $\mathrm{Mg}-\mathrm{Hg}$ alloys can be calculated or measured. ${ }^{12)}$ With a content of $\mathrm{Hg} 0-6$ mass $\%$, the density of $\mathrm{Mg}-\mathrm{Hg}$ alloys can be expressed as eq. (8). The error between eq. (8) and the measured values is less than $2 \mathrm{~kg} / \mathrm{m}^{3}$.

$$
\rho=1737.4+16.8 C_{0}
$$

$S_{\mathrm{MH}} / S$ is the area fraction of eutectic $\mathrm{Mg}_{3} \mathrm{Hg}$. Because the morphology of the $\mathrm{Mg}-\mathrm{Hg}$ alloy is a divorced eutectic, $\alpha-\mathrm{Mg}$ and $\mathrm{Mg}_{3} \mathrm{Hg}$ form separately (Fig. 4). $S_{\mathrm{MH}} / S$ can be obtained using quantitative metallography methods by measuring the area fraction of $\mathrm{Mg}_{3} \mathrm{Hg}$ in metallographes. Quantitative metallographic analysis was carried out by Image-Pro Plus software. $S_{\mathrm{MH}}$ is the sum of the area of 8 circles in Fig. 4, and $S=a \times b$.

According to eq. (7), the maximum solid solubility of $\mathrm{Hg}$ in $\mathrm{Mg}$ was calculated and is shown in Fig. 5. Under the nonequilibrium solidification condition, the diffusion of $\mathrm{Hg}$ in primary $\alpha-\mathrm{Mg}$ was not sufficient, so the maximum solid solubility shifted towards a lower $\mathrm{Hg}$ content.

The maximum solid solubility of $\mathrm{Mg}-2.4$ mass $\% \mathrm{Hg}$ under the non-equilibrium solidification condition was 0.81 and 0.69 mass \% with cooling rates of 0.67 and $2 \mathrm{~K} / \mathrm{s}$, respectively. The maximum solid solubility decreased as cooling rate increased and increased as $\mathrm{Hg}$ content increased. These results show that the maximum solid solubility of $\mathrm{Hg}$ in $\mathrm{Mg}$ under the non-equilibrium solidification condition relates to the diffusion process of the $\mathrm{Hg}$ element. Reducing the cooling rate and increasing the $\mathrm{Hg}$ content promotes the

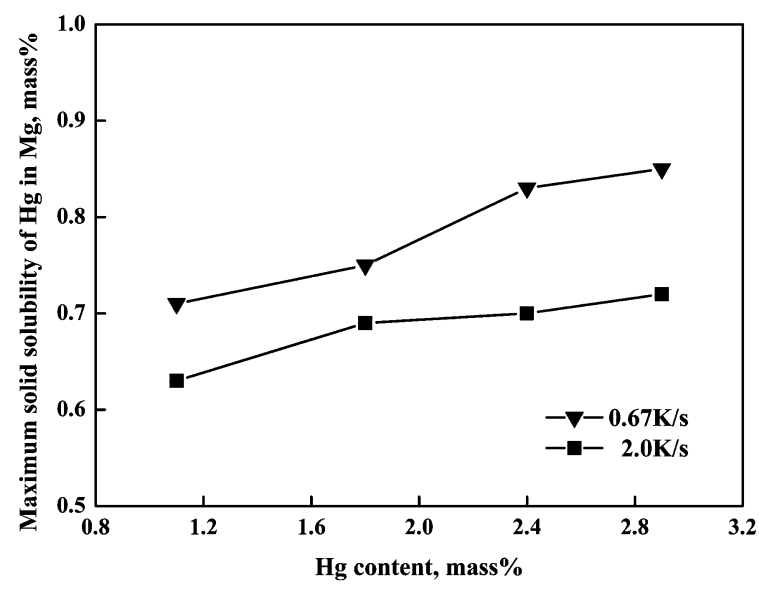

Fig. 5 Relationship between $\mathrm{Hg}$ content and maximum solid solubility under the non-equilibrium solidification condition.

diffusion of $\mathrm{Hg}$ into the solid phase and increases the solubility limit.

This method of estimating the shifting distance of the maximum solid solubility is not restricted to $\mathrm{Mg}-\mathrm{Hg}$ alloys. If there exists a divorced eutectic and the area fraction of the second phase can be measured, then the shifting distance of the maximum solid solubility can be estimated.

\section{Conclusions}

$\mathrm{Mg}-\mathrm{Hg}$ alloys with up to 2.9 mass $\% \mathrm{Hg}$ have a two-phase structure consisting of a solid solution phase and a divorced eutectic, which precipitates at the grain boundaries. As the $\mathrm{Hg}$ content increased, the amount of eutectic $\mathrm{Mg}_{3} \mathrm{Hg}$ increased and the eutectic at the grain boundary changed from a discontinuous to a continuous network. A method is proposed to estimate the maximum solid solubility of $\mathrm{Hg}$ in $\mathrm{Mg}$ under the non-equilibrium solidification condition. The maximum solid solubility decreased as the cooling rate increased and increased as the $\mathrm{Hg}$ content increased.

\section{REFERENCES}

1) M. G. Medeiros and E. G. Dow: J. Power Sources 80 (1999) 78-82.

2) H. Zhao, P. Bian and D. Ju: J. Environ. Sci. 21 (2009) S88-S91.

3) K. Yu, X. Tan, Y. Hu, F. Chen and S. Li: Corros. Sci. 53 (2011) 20352040.

4) Y. Feng, R. Wang, K. Yu, C. Peng, J. Zhang and C. Zhang: J. Alloy. Compd. 473 (2009) 215-219.

5) G. Song and A. Atrens: Adv. Eng. Mater. 5 (2003) 837-858.

6) L. Wang, P. Li and L. He: Russ. J. Electrochem. 47 (2011) 900-907.

7) R. P. Beck: Rev. Trav. Chim. 41 (1922) 353-399.

8) M. Y. Vyazner, I. P. Vyatkin and S. V. Mushkov: Izv. Akad. Nauk. SSSR Met. 3 (1975) 237-239 (in Russian).

9) D. Dube, A. Couture, Y. Carbonneau, M. Fiset, R. Angers and R. Tremblay: Int. J. Cast Met. Res. 11 (1998) 39-144.

10) W. T. Collins and L. F. Mondolfo: Trans. Metall. Soc. AIME 233 (1965) 1671-1676.

11) A. A. Nayeb-Hashemi and J. B. Clark: Bull. Alloy Phase Diagr. 8 (1987) 65-70.

12) T. N. Lipchin, S. V. Mushkov and I. P. Vyatkin: Met. Sci. Heat Treat. 16 (1974) 1037-1038.

13) A. K. Dahle, Y. C. Lee and M. D. Nave: J. Light Met. 1 (2001) 61-72.

14) Z. Cui: Metallography Principle and Heat Treatment, (China Machine Press, Beijing, 1994). 